\title{
1 Infectious SARS-CoV-2 is emitted in aerosols
}

3 Seth A. Hawks ${ }^{1}$, Aaron J. Prussin II², Sarah C. Kuchinsky ${ }^{1}$, Jin Pan², Linsey C. Marr ${ }^{2}$, Nisha K.

4 Duggal $^{1^{*}}$

5

$6{ }^{1}$ Department of Biomedical Sciences and Pathobiology, Virginia-Maryland College of Veterinary

7 Medicine, Virginia Polytechnic Institute and State University, Blacksburg, VA

$8{ }^{2}$ Department of Civil and Environmental Engineering, Virginia Polytechnic Institute and State

9 University, Blacksburg, VA

10

11 * Corresponding author: nduggal@vt.edu, phone (540) 231-6705, address 1981 Kraft Dr,

12 Blacksburg, VA 24060

13 


\section{Abstract}

15 Respiratory viruses such as SARS-CoV-2 are transmitted in respiratory droplets and aerosols,

16 which are released during talking, breathing, coughing, and sneezing. Non-contact transmission

17 of SARS-CoV-2 has been demonstrated, suggesting transmission in aerosols. Here we

18 demonstrate that golden Syrian hamsters emit infectious SARS-CoV-2 in aerosols, prior to and

19 concurrent with the onset of mild clinical signs of disease. The average emission rate is 25

20 infectious virions/hour on days 1 and 2 post-inoculation, with average viral RNA levels 200-fold

21 higher than infectious virus in aerosols. Female hamsters have delayed kinetics of viral

22 shedding in aerosols compared to male hamsters, with peak viral emission for females on dpi 2

23 and for males on dpi 1 . The majority of virus is contained within aerosols $<8 \mu \mathrm{m}$ in size. Thus,

24 we provide direct evidence that, in hamsters, SARS-CoV-2 is an airborne virus. 


\section{Introduction}

26 SARS-CoV-2 is a respiratory virus that has caused more than 190 million cases and 4.1 million

27 deaths, as of July 2021 [1]. Respiratory droplets and aerosol particles (aerosols), which may

28 contain virus, are expelled during coughing, sneezing, talking, and breathing and can vary

29 widely in size from less than $1 \mu \mathrm{m}$ to greater than $100 \mu \mathrm{m}[2,3]$. Their size significantly impacts

30 transmission risk and mode due to differences in the way that droplets and aerosols travel

31 through the air. There is a continuum of maximum distances that particles can reach. Those

32 smaller than $10 \mu \mathrm{m}$ remain suspended in air for many minutes to hours, during which they can

33 travel long distances; this does not rule out their potential to transmit at close range, too.

Infectious SARS-CoV-2 has been cultured from aerosols sampled near COVID-19

patients [4-7]. SARS-CoV-2 has also been isolated from aerosols $<1 \mu \mathrm{m}$ within a car driven by a

COVID-19 patient with mild illness [8]. The collection of exhaled breath condensate (EBC) is a

non-invasive sampling method of respiratory droplets and aerosols that has been used to

assess the airborne transmission potential of respiratory viruses, including seasonal human

coronaviruses, influenza viruses, and rhinoviruses [9-12]. For COVID-19 patients, the emission

rate of SARS-CoV-2 RNA in EBC was estimated to be $>1$ million viral RNA copies/hour by

41 breathing $[13,14]$. In non-human primates, SARS-CoV-2 RNA has also been detected in EBC

42 collected from inoculated animals $[15,16]$.

43 Hamsters are a naturally-susceptible animal model for SARS-CoV-2 transmission that

44 develop few clinical signs of disease [17-22]. Unlike mice, hamsters model asymptomatic

45 infection, which has been suggested to be the most important component of community

46 transmission of SARS-CoV-2 [23, 24]. Oral swabs from inoculated hamsters contain high levels

47 of infectious virus, with levels similar to saliva collected from COVID-19 patients [25, 26].

48 Importantly, inoculated hamsters have been shown to transmit SARS-CoV-2 to naïve hamsters

49 via non-contact transmission [17, 18, 22], suggesting SARS-CoV-2 may be transmitted between 
animals via aerosols released during breathing. However, infectious SARS-CoV-2 has not yet

51 been cultured from aerosols released from infected animals.

In this study, we seek to determine the shedding kinetics of infectious SAS-CoV-2 in aerosols. We find that hamsters inoculated with SARS-CoV-2 emit infectious SARS-CoV-2 into

54 the air prior to and concurrent with the onset of clinical signs of disease. Viral titers decrease

55 quickly over time, whereas viral RNA is detected in the air for many days post-inoculation. Male

56 hamsters shed virus in the air earlier than female hamsters. We also find that aerosols $<8 \mu \mathrm{m}$

57 contain the majority of airborne virus.

\section{Materials and Methods}

60 Viruses and cell lines. Inoculations were performed using SARS-CoV-2 strain USA-WA1/2020

61 (BEI Resources), which was passaged once in Vero E6 cells followed by once in Vero cells

62 upon receipt. Vero and Vero E6 cells were cultivated in DMEM containing 5\% FBS and 1\%

63 penicillin-streptomycin and maintained at $37^{\circ} \mathrm{C}$ and $5 \% \mathrm{CO}_{2}$.

64

Animal studies. All animal studies were performed in two independent experiments. Three- to six-week-old golden Syrian hamsters (Envigo) were inoculated intranasally with $5 \log _{10}$ PFU of SARS-CoV-2 in $100 \mu$ L PBS. Hamsters were weighed and monitored for clinical signs of illness daily. Air samples, oral swabs, nasal washes, fur swabs, and rectal swabs were collected daily. At the termination of studies, or when clinical signs of disease such as $15 \%$ weight loss were

70 present, hamsters were euthanized via $\mathrm{CO}_{2}$ inhalation, and bronchoalveolar lavage (BAL) fluid

71 and lung tissue were collected. Relative humidity and temperature in the animal facility during

72 the studies were $27.1 \pm 11 \%$ and $24.6 \pm 0.8^{\circ} \mathrm{C}$, respectively.

\section{Aerosol sampling and measurement.}


75 Chamber and nosecone. Aerosols generated by hamsters were sampled using two different

76 approaches. In the first, infected hamsters were placed in a $2 \mathrm{~L}$ sealed chamber, in which they

77 were allowed to move freely. Air was supplied through an inlet to the chamber, and aerosols

78 were sampled through an outlet. This approach captured total aerosols produced in exhaled

79 breath, released from the fur, and resuspended from the chamber floor by the hamster's activity.

80 The second approach captured aerosols produced in exhaled breath only. Infected hamsters

81 were anesthetized with a mixture of ketamine $(100 \mathrm{mg} / \mathrm{kg})$ and xylazine $(10 \mathrm{mg} / \mathrm{kg})$ administered

82 by intraperitoneal (i.p.) injection. After the hamster was fully immobile, a non-rebreather

83 nosecone (Kent Scientific, VetFlo-0802) was placed on the hamster. Air was provided through

84 the nosecone's inlet tube, and aerosols were sampled via the outlet port.

Infectious virus collection. A condensation sampler (Aerosol Devices Inc. Series 110A) was

connected to the outlet of the chamber or nosecone. The sampler was operated at $1.5 \mathrm{~L} / \mathrm{min}$ for separate aerosols by size, a cyclone (URG 2000-30E-5-2.5-S) that removes aerosols larger than $8 \mu \mathrm{m}$ at the sampling flow rate used here was installed upstream of the condensation

91 sampler. Samples were collected for 30 minutes with the cyclone and 30 minutes without the

92 cyclone. For 4 hamsters, the cyclone was used during the first 30-minute period, and for 4

93 hamsters, the cyclone was used during the second 30-minute period.

95 Aerosol size distribution. An aerodynamic particle sizer (TSI 3321) was connected to the outlet 96 of the chamber or nosecone to measure the aerosol size distribution for 15 minutes in 1 minute

97 intervals at a flow rate of $1 \mathrm{~L} / \mathrm{min}$, with makeup air provided at the same flow rate. This

98 instrument detects aerosols over the size range 0.5-20 $\mu \mathrm{m}$. Background concentrations 
measured in an empty chamber and nosecone were subtracted to estimate the contribution from the hamsters alone.

\section{Viral quantification.}

103 Plaque assays. Infectious virus was quantified via Vero cell plaque assay. Briefly, samples were 104 serially diluted, plated onto confluent Vero cells in a 6-well plate, and incubated for 1 hour at $10537^{\circ} \mathrm{C}$. After a 1 -hour adsorption, $2 \mathrm{~mL}$ of an $0.8 \%$ agarose overlay medium was added to the 106 wells. Plates were incubated for 1 day at $37^{\circ} \mathrm{C}$, after which a second $2 \mathrm{~mL}$ overlay containing $1073 \%$ neutral red was added to the wells. One day later, plaques were counted. The limit of 108 detection was $1.4 \log _{10} \mathrm{PFU} / \mathrm{swab}$ (oral/fur/rectal) and BAL fluid, $0.3 \log _{10} \mathrm{PFU} /$ air sample, and $1090.7 \log _{10}$ PFU/nasal wash.

Real-time RT-PCR. Viral RNA was extracted from samples via Qiagen QIAamp Viral RNA Mini

112 kit. RNA was quantified by real-time RT-PCR using the 2019-nCoV RUO primer/probe kit (IDT 113 10006713) and BioRad iTaq Universal Probes One-Step kit. Synthetic SARS-CoV-2 RNA (BEI 114 NR-52358) was used for a standard curve. The limit of detection was $1.33 \log _{10}$ RNA copies/oral swab, $1.66 \log _{10}$ RNA copies/air sample, and $1.38 \log _{10}$ RNA copies/nasal wash.

Statistics. Samples were compared using a t-test or mixed-effects analysis with Sidak's correction for multiple comparisons. All statistics were performed in GraphPad Prism 9.

120 Ethics statement. All animal experiments were approved by the Institutional Biosafety

121 Committee and Institutional Animal Care and Use Committee at Virginia Polytechnic Institute 122 and State University (IACUC protocol 20-184). All experiments involving infectious SARS-CoV-2 123 were performed in BSL3 and ABSL3 containment. 


\section{Results}

126 Aerosol generation by hamsters. To test whether inoculated animals shed SARS-CoV-2 in

127 aerosols, we established two aerosol sampling methods for hamsters. In the first method,

128 animals were allowed to move freely within an empty $2 \mathrm{~L}$ chamber (Figure $1 \mathrm{~A}$ ). In the second

129 method, animals were anesthetized, and a nosecone was placed over the nose and mouth

130 (Figure 1B). Aerosols were sampled via an outlet port from the chamber or nosecone.

We measured aerosols produced by uninfected hamsters and calculated the emission

132 rate. Using the chamber, we found an average of 700 aerosol particles emitted per minute per

133 hamster (Figure 1C), with $99.9 \%$ of them $<10 \mu \mathrm{m}$ in size (Supplementary Figure 1). Using the

134 nosecone, we found an average of 1 aerosol particle emitted per minute per hamster, which

135 was significantly fewer than the chamber approach $(p<0.05)$. The size distribution was similar in both cases, with very small particles being the most abundant.

Infectious SARS-CoV-2 is emitted in aerosols. Hamsters were inoculated intranasally with SARS-CoV-2 strain USA-WA1/2020. Mild weight loss occurred from days post-inoculation (dpi)

1402 through 5 (Figure 2A). Oral swabs and nasal washes were collected daily. Virus peaked on

141 dpi 1 in the oral swabs at $3.5 \log _{10}$ PFU/swab and on dpi 2 in the nasal washes at $3.9 \log _{10}$

142 PFU/wash (Figure 2B and C). Significantly higher viral titers were observed in nasal washes

143 from males compared to females on dpi 1 , with a 5,000-fold difference $(p<0.001)$. Viral titers for

144 females peaked one day later than males. Viral titers decreased over time, with infectious virus

145 below the limit of detection by dpi 5 for most animals. Samples were tested for RNA, which was

146 detectable through dpi 10 (Figure 2E and F). Sex-specific differences were not observed for

147 viral RNA levels.

$148 \quad$ Air samples were collected daily for 1 hour using a condensation sampler, which

149 maintains viral infectivity [27]. Infectious virus was detected in aerosols collected on dpi 1 and 2

150 from males, with a mean emission rate of $1.5 \log _{10}$ PFU/hour, and infectious virus was detected 
on dpi 2 from females, with a mean emission rate of $1.0 \log _{10}$ PFU/hour (Figure 2D).

152 Significantly greater infectious viral titers were detected in air samples from males compared to

153 females on dpi $1(p<0.01)$. The overall mean emission rate across dpi 1 and 2 was $1.4 \log _{10}$

154 PFU/hour. A majority (75\%) of inoculated animals released detectable levels of virus in the air

155 on dpi 2, and emission rates ranged from 0.9 to $1.8 \log _{10}$ PFU/hour. Infectious virus was below

156 the limit of detection in air samples collected after dpi 2. Air samples were also tested for viral

157 RNA; viral RNA was detected through dpi 5, with levels below the limit of detection by dpi 10

158 (Figure 2G). Sex-specific differences were not observed for viral RNA levels in the air. For

159 samples with detectable infectious virus, the RNA levels were approximately 200 -fold higher

160 than PFU levels on dpi 1 and 2 for males and approximately 300-fold higher than PFU levels for

161 females on dpi 2. Together, these data show that infectious SARS-CoV-2 is emitted in aerosols

162 early in infection, prior to and concurrent with the onset of mild clinical signs of disease.

Aerosols $<8 \mu \mathrm{m}$ contain infectious SARS-CoV-2. Once we established the infectious window for airborne virus, we inoculated additional hamsters in order to test whether small aerosols contain infectious SARS-CoV-2. Here, we shortened the air sampling time to 30 minutes. Male hamsters were used, as virus was more readily detected in their air samples compared to females' air samples. To test whether the virus detected in the air was residual inoculum, we collected an air sample at 4 hours post-inoculation using the chamber; no virus was detected (Figure 3A). Then, we collected air samples on dpi 1 and 2 in the chamber, with and without a

171 cyclone separator, which removed aerosols $>8 \mu \mathrm{m}$, placed upstream of the condensation

172 sampler. We detected similar titers in samples collected with and without the cyclone separator,

173 with no statistical significance in the difference in mean titers on dpi $1(p=0.34)$ or dpi $2(p=0.37)$,

174 indicating that size restriction did not alter the amount of virus detected (Figure 3A). To test

175 whether airborne SARS-CoV-2 was detectable in the breath, we anesthetized the hamsters and 176 collected their breath from the nosecone for one hour. Infectious virus was not detectable. 
177 However, the breath rate was very low during anesthesia (13 \pm 2 breaths/minute), and very few

178 total respiratory aerosols were collected with this method compared to the chamber method

179 (Figure 1C).

High levels of virus were detectable in oral swabs, nasal washes, and BAL fluid collected

181 from the animals (Figure 3B-D). A low level of virus was detected in fur and rectal swabs taken

182 from the animals, which indicates that some of the airborne virus detected in the chamber could

183 be resuspended from the body (Figure 3E and F). Together, these results indicate that SARS-

184 CoV-2 is emitted primarily in small aerosols $<8 \mu \mathrm{m}$.

\section{Discussion}

187 In this study, we found that hamsters emitted infectious SARS-CoV-2 in aerosols primarily $<8$

$188 \mu \mathrm{m}$ in size in the absence of severe disease, with an emission rate of $1.4 \log _{10} \mathrm{PFU} / \mathrm{hour}$

189 (Figures 2 and 3). Peak emission of infectious virus was delayed by 1 day for females compared

190 to males. SARS-CoV-2 viral RNA was detected in aerosols and the upper respiratory tract for a

191 longer duration than infectious virus. The upper and lower respiratory tract contained high titers

192 of virus, suggesting that the virus isolated from the air was primarily derived from the breath.

193 However, we found that the fur was contaminated with low levels of infectious virus, indicating

194 that virus resuspended from the fur may also be a viable mechanism of SARS-CoV-2 emission

195 into the air.

196 Aerosols $<8 \mu \mathrm{m}$ in size can remain airborne and be inhaled. Thus, our results suggest

197 that airborne transmission is likely a major driver of SARS-CoV-2 transmission. Our studies

198 support reports of infectious SARS-CoV-2 collected from aerosols near COVID-19 patients [4-

199 7], as well as studies showing non-contact transmission of SARS-CoV-2 between ferrets and

200 hamsters [17, 18, 22], including one study that demonstrated transmission over a 1-meter

201 distance [28]. Some previous studies have been unable to culture virus from air samples from

202 COVID-19 patients or inoculated non-human primates due to unknown collection times post- 
onset of disease or the use of air sampling equipment or buffers that do not maintain viral

204 infectivity $[16,29]$. Our results support the idea that transmission is likely to occur prior to or

205 concurrent with symptom onset or in the absence of clinical disease, supporting studies that

206 have found that asymptomatic infection is a major driver of community transmission [23, 24].

207 Identifying the modes of SARS-CoV-2 transmission is critical to designing interventions to

208 effectively prevent transmission, and our results support the use of masks and ventilation to

209 reduce SARS-CoV-2 transmission.

210 This study was limited by our inability to collect EBC from the hamsters. We were unable

211 to detect infectious virus directly from the breath when anesthetized; however, anesthesia

212 decreased the breath rate of hamsters, and we detected 700 -fold fewer aerosol particles with

213 this method (Figure 1). Thus, given the detection of infectious virus on the fur, we cannot

214 exclude that virus resuspended from the fur during movement may have contributed to the

215 particles that we detected using the chamber method. Movement in guinea pigs has been

216 shown to increase influenza particles in the air by increasing the resuspension of dust particles

217 from the body [30]. The contribution of resuspended aerosols to SARS-CoV-2 airborne

218 transmission has not been studied.

219 Sex-specific differences in COVID-19 disease severity are widely reported, with more

220 severe disease in men [31, 32]. Here, we detected a delay in transmission potential in female

221 hamsters compared to male hamsters. It is unclear whether these sex-specific differences in

222 infectious viral shedding detected are relevant to human transmission. Interestingly, viral RNA

223 levels in air samples were not significantly different between male and female hamsters,

224 suggesting that a female-specific factor may enhance the release of defective virions. Most

225 studies detect viral RNA, which may lead to the underestimation of differences in viral

226 transmission potential between sexes. Sex-specific differences in infectious viral titers have not

227 been observed by other groups, but differences in timing of samples collected may be relevant, 
as the largest difference was observed on dpi 1 in this study, which was not tested in other studies [33, 34].

Public health agencies have recently begun describing SARS-CoV-2 as an airborne virus. Here, we show that infectious virus is indeed culturable from the air early after infection,

232 with the majority of aerosols containing infectious virus $<8 \mu \mathrm{m}$ in size. This suggests that SARS-

233 CoV-2 may be maintained in the air for hours and over larger distances that previously

234 recognized, with ventilation being an important tool for preventing transmission. Future studies

235 will be critical for establishing the transmission potential of small aerosols containing SARS-

236 CoV-2.

\section{Acknowledgements}

239 Funding for this project was provided by a Virginia Tech Center for Emerging, Zoonotic, and

240 Arthropod-borne Pathogens (CeZAP) seed grant and a Virginia Tech Institute for Critical

241 Technology and Applied Science (ICTAS) Junior Faculty Award. Support was also provided by

242 the Virginia Tech Fralin Life Sciences Institute and the BIOTRANS Interdisciplinary Graduate

243 Education Program. We thank Dr. Amy Rizzo and TRACSS staff for contributions to the

244 development of the animal protocol and animal husbandry. The following reagents were

245 obtained through BEI Resources, NIAID, NIH: SARS-CoV-2 isolate USA-WA1/2020, NR-52281

246 and Quantitative Synthetic RNA from SARS-CoV-2, NR-52538. Figure 1 was created with

247 BioRender.com.

\section{References}

1. Organization WH. WHO Coronavirus (COVID-19) Dashboard [July 2021]. Available from: https://covid19.who.int/.

254 2019;16(150):20180298. Epub 2019/04/09. doi: 10.1098/rsif.2018.0298. PubMed PMID:

255 30958176; PubMed Central PMCID: PMCPMC6364647.

$256 \quad 3 . \quad$ L. Morawska GRJ, Z.D. Ristovski, M. Hargreaves, K. Mengersen, S. Corbett, C.Y.H.

257 Chao, Y. Li, D. Katoshevski,. Size distribution and sites of origin of droplets expelled from the 
258

259

260

261

262

263

264

265

266

267

268

269

270

271

272

273

274

275

276

277

278

279

280

281

282

283

284

285

286

287

288

289

290

291

292

293

294

295

296

297

298

299

300

301

302

303

304

305

306

307

human respiratory tract during expiratory activities,. Journal of Aerosol Science. 2009;40(3):25626. doi: 10.1016/j.jaerosci.2008.11.002.

4. Lednicky JA, Lauzardo M, Hugh Fan Z, Jutla A, Tilly TB, Gangwar M, et al. Viable SARS-CoV-2 in the air of a hospital room with COVID-19 patients. Int J Infect Dis. 2020. Epub 2020/09/20. doi: 10.1016/j.ijid.2020.09.025. PubMed PMID: 32949774; PubMed Central PMCID: PMCPMC7493737.

5. Santarpia JL, Rivera DN, Herrera VL, Morwitzer MJ, Creager HM, Santarpia GW, et al. Aerosol and surface contamination of SARS-CoV-2 observed in quarantine and isolation care. Sci Rep. 2020;10(1):12732. Epub 2020/07/31. doi: 10.1038/s41598-020-69286-3. PubMed PMID: 32728118; PubMed Central PMCID: PMCPMC7391640.

6. Guo ZD, Wang ZY, Zhang SF, Li X, Li L, Li C, et al. Aerosol and Surface Distribution of Severe Acute Respiratory Syndrome Coronavirus 2 in Hospital Wards, Wuhan, China, 2020. Emerg Infect Dis. 2020;26(7):1583-91. Epub 2020/04/11. doi: 10.3201/eid2607.200885. PubMed PMID: 32275497; PubMed Central PMCID: PMCPMC7323510.

7. Liu Y, Ning Z, Chen Y, Guo M, Liu Y, Gali NK, et al. Aerodynamic analysis of SARSCoV-2 in two Wuhan hospitals. Nature. 2020;582(7813):557-60. Epub 2020/04/28. doi: 10.1038/s41586-020-2271-3. PubMed PMID: 32340022.

8. Lednicky JA, Lauzardo M, Alam MM, Elbadry MA, Stephenson CJ, Gibson JC, et al. Isolation of SARS-CoV-2 from the air in a car driven by a COVID patient with mild illness. Int J Infect Dis. 2021;108:212-6. Epub 2021/04/27. doi: 10.1016/j.ijid.2021.04.063. PubMed PMID: 33901650; PubMed Central PMCID: PMCPMC8064821.

9. Leung NHL, Chu DKW, Shiu EYC, Chan KH, McDevitt JJ, Hau BJP, et al. Respiratory virus shedding in exhaled breath and efficacy of face masks. Nat Med. 2020;26(5):676-80. Epub 2020/05/07. doi: 10.1038/s41591-020-0843-2. PubMed PMID: 32371934.

10. Yan J, Grantham M, Pantelic J, Bueno de Mesquita PJ, Albert B, Liu F, et al. Infectious virus in exhaled breath of symptomatic seasonal influenza cases from a college community. Proc Natl Acad Sci U S A. 2018;115(5):1081-6. Epub 2018/01/20. doi:

10.1073/pnas.1716561115. PubMed PMID: 29348203; PubMed Central PMCID: PMCPMC5798362.

11. Milton DK, Fabian MP, Cowling BJ, Grantham ML, McDevitt JJ. Influenza virus aerosols in human exhaled breath: particle size, culturability, and effect of surgical masks. PLoS Pathog. 2013;9(3):e1003205. Epub 2013/03/19. doi: 10.1371/journal.ppat.1003205. PubMed PMID: 23505369; PubMed Central PMCID: PMCPMC3591312.

12. Tovey ER, Stelzer-Braid S, Toelle BG, Oliver BG, Reddel HK, Willenborg CM, et al. Rhinoviruses significantly affect day-to-day respiratory symptoms of children with asthma. $\mathrm{J}$ Allergy Clin Immunol. 2015;135(3):663-9 e12. Epub 2014/12/06. doi: 10.1016/j.jaci.2014.10.020. PubMed PMID: 25476729; PubMed Central PMCID: PMCPMC7173323.

13. Zhou L, Yao M, Zhang X, Hu B, Li X, Chen H, et al. Detection of SARS-CoV-2 in Exhaled Breath from COVID-19 Patients Ready for Hospital Discharge. medRxiv. 2020:2020.05.31.20115196. doi: 10.1101/2020.05.31.20115196.

14. Ma J, Qi X, Chen H, Li X, Zhang Z, Wang H, et al. Coronavirus Disease 2019 Patients in Earlier Stages Exhaled Millions of Severe Acute Respiratory Syndrome Coronavirus 2 Per Hour. Clinical Infectious Diseases. 2020. doi: 10.1093/cid/ciaa1283.

15. Edwards DA, Ausiello D, Salzman J, Devlin T, Langer R, Beddingfield BJ, et al. Exhaled aerosol increases with COVID-19 infection, age, and obesity. Proc Natl Acad Sci U S A. 2021;118(8). Epub 2021/02/11. doi: 10.1073/pnas.2021830118. PubMed PMID: 33563754; PubMed Central PMCID: PMCPMC7923364.

16. Zhang C, Guo Z, Zhao Z, Wang T, Li L, Miao F, et al. SARS-CoV-2 Aerosol Exhaled by Experimentally Infected Cynomolgus Monkeys. Emerg Infect Dis. 2021;27(7):1979-81. Epub 2021/06/22. doi: 10.3201/eid2707.203948. PubMed PMID: 34152969. 
308

309

310

311

312

313

314

315

316

317

318

319

320

321

322

323

324

325

326

327

328

329

330

331

332

333

334

335

336

337

338

339

340

341

342

343

344

345

346

347

348

349

350

351

352

353

354

355

356

357

358

17. Sia SF, Yan LM, Chin AWH, Fung K, Choy KT, Wong AYL, et al. Pathogenesis and transmission of SARS-CoV-2 in golden hamsters. Nature. 2020;583(7818):834-8. Epub 2020/05/15. doi: 10.1038/s41586-020-2342-5. PubMed PMID: 32408338; PubMed Central PMCID: PMCPMC7394720.

18. Chan JF, Zhang AJ, Yuan S, Poon VK, Chan CC, Lee AC, et al. Simulation of the clinical and pathological manifestations of Coronavirus Disease 2019 (COVID-19) in golden Syrian hamster model: implications for disease pathogenesis and transmissibility. Clin Infect Dis. 2020. Epub 2020/03/28. doi: 10.1093/cid/ciaa325. PubMed PMID: 32215622; PubMed Central PMCID: PMCPMC7184405.

19. Imai M, Iwatsuki-Horimoto K, Hatta M, Loeber S, Halfmann PJ, Nakajima N, et al. Syrian hamsters as a small animal model for SARS-CoV-2 infection and countermeasure development. Proc Natl Acad Sci U S A. 2020;117(28):16587-95. Epub 2020/06/24. doi: 10.1073/pnas.2009799117. PubMed PMID: 32571934; PubMed Central PMCID: PMCPMC7368255.

20. Chak-Yiu Lee A, Zhang AJ, Fuk-Woo Chan J, Li C, Fan Z, Liu F, et al. Oral SARS-CoV-2 inoculation establishes subclinical respiratory infection with virus shedding in golden Syrian hamsters. Cell Rep Med. 2020:100121. Epub 2020/09/29. doi: 10.1016/j.xcrm.2020.100121. PubMed PMID: 32984855; PubMed Central PMCID: PMCPMC7508015.

21. Rosenke K, Meade-White K, Letko MC, Clancy C, Hansens F, Liu Y, et al. Defining the Syrian hamster as a highly susceptible preclinical model for SARS-CoV-2 infection. bioRxiv. 2020. Epub 2020/10/01. doi: 10.1101/2020.09.25.314070. PubMed PMID: 32995767; PubMed Central PMCID: PMCPMC7523093.

22. Chan JF, Yuan S, Zhang AJ, Poon VK, Chan CC, Lee AC, et al. Surgical mask partition reduces the risk of non-contact transmission in a golden Syrian hamster model for Coronavirus Disease 2019 (COVID-19). Clin Infect Dis. 2020. Epub 2020/05/31. doi: 10.1093/cid/ciaa644. PubMed PMID: 32472679; PubMed Central PMCID: PMCPMC7314229.

23. Johansson MA, Quandelacy TM, Kada S, Prasad PV, Steele M, Brooks JT, et al. SARSCoV-2 Transmission From People Without COVID-19 Symptoms. JAMA Netw Open. 2021;4(1):e2035057. Epub 2021/01/08. doi: 10.1001/jamanetworkopen.2020.35057. PubMed PMID: 33410879; PubMed Central PMCID: PMCPMC7791354.

24. Subramanian $\mathrm{R}, \mathrm{He} \mathrm{Q}$, Pascual M. Quantifying asymptomatic infection and transmission of COVID-19 in New York City using observed cases, serology, and testing capacity. Proc Natl Acad Sci U S A. 2021;118(9). Epub 2021/02/12. doi: 10.1073/pnas.2019716118. PubMed PMID: 33571106; PubMed Central PMCID: PMCPMC7936345.

25. Iwasaki S, Fujisawa S, Nakakubo S, Kamada K, Yamashita Y, Fukumoto T, et al. Comparison of SARS-CoV-2 detection in nasopharyngeal swab and saliva. J Infect. 2020;81(2):e145-e7. Epub 2020/06/07. doi: 10.1016/j.jinf.2020.05.071. PubMed PMID: 32504740; PubMed Central PMCID: PMCPMC7270800 interests.

26. Zhu J, Guo J, Xu Y, Chen X. Viral dynamics of SARS-CoV-2 in saliva from infected patients. J Infect. 2020;81(3):e48-e50. Epub 2020/07/01. doi: 10.1016/j.jinf.2020.06.059. PubMed PMID: 32593658; PubMed Central PMCID: PMCPMC7316041.

27. Lednicky JA, Lauzardo M, Fan ZH, Jutla A, Tilly TB, Gangwar M, et al. Viable SARSCoV-2 in the air of a hospital room with COVID-19 patients. medRxiv. 2020. Epub 2020/08/15. doi: 10.1101/2020.08.03.20167395. PubMed PMID: 32793914; PubMed Central PMCID: PMCPMC7418726.

28. Kutter JS, de Meulder D, Bestebroer TM, Lexmond P, Mulders A, Richard M, et al. SARS-CoV and SARS-CoV-2 are transmitted through the air between ferrets over more than one meter distance. Nat Commun. 2021;12(1):1653. Epub 2021/03/14. doi: 10.1038/s41467021-21918-6. PubMed PMID: 33712573; PubMed Central PMCID: PMCPMC7955093.

29. Ong SWX, Tan YK, Coleman KK, Tan BH, Leo YS, Wang DL, et al. Lack of viable severe acute respiratory coronavirus virus 2 (SARS-CoV-2) among PCR-positive air samples 
from hospital rooms and community isolation facilities. Infect Control Hosp Epidemiol. 2021:1-6. Epub 2021/01/26. doi: 10.1017/ice.2021.8. PubMed PMID: 33487210; PubMed Central PMCID: PMCPMC7870907.

30. Asadi S, Gaaloul Ben Hnia N, Barre RS, Wexler AS, Ristenpart WD, Bouvier NM. Influenza A virus is transmissible via aerosolized fomites. Nat Commun. 2020;11(1):4062. Epub 2020/08/20. doi: 10.1038/s41467-020-17888-w. PubMed PMID: 32811826; PubMed Central PMCID: PMCPMC7435178.

31. Peckham H, de Gruijter NM, Raine C, Radziszewska A, Ciurtin C, Wedderburn LR, et al. Male sex identified by global COVID-19 meta-analysis as a risk factor for death and ITU admission. Nat Commun. 2020;11(1):6317. Epub 2020/12/11. doi: 10.1038/s41467-020-197416. PubMed PMID: 33298944; PubMed Central PMCID: PMCPMC7726563. 32. GlobalHealth5050. The Sex, Gender and COVID-19 Project [July 2021]. Available from: https://globalhealth5050.org/the-sex-gender-and-covid-19-project/.

33. Dhakal S, Ruiz-Bedoya CA, Zhou R, Creisher PS, Villano JS, Littlefield K, et al. Sex Differences in Lung Imaging and SARS-CoV-2 Antibody Responses in a COVID-19 Golden Syrian Hamster Model. mBio. 2021:e0097421. Epub 2021/07/14. doi: 10.1128/mBio.00974-21. PubMed PMID: 34253053.

34. Rosenke K, Meade-White K, Letko M, Clancy C, Hansen F, Liu Y, et al. Defining the Syrian hamster as a highly susceptible preclinical model for SARS-CoV-2 infection. Emerg Microbes Infect. 2020;9(1):2673-84. Epub 2020/12/01. doi: 10.1080/22221751.2020.1858177. PubMed PMID: 33251966; PubMed Central PMCID: PMCPMC7782266. 
A.

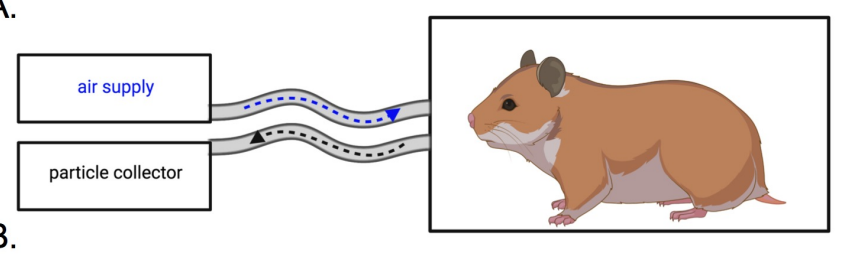

B.

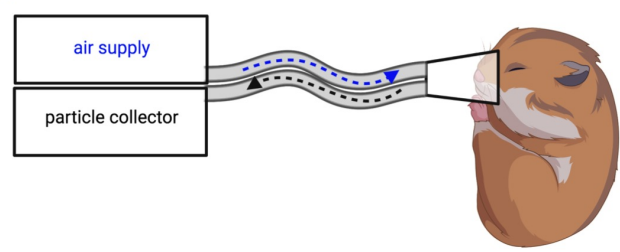

C.

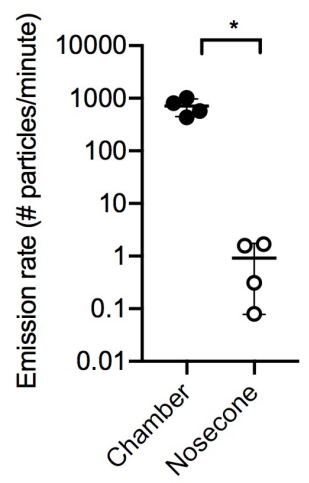

382 Figure 1. Air sampling methods. Aerosols were collected using a condensation sampler or an

383 aerodynamic particle sizer. (A) Air was collected from awake hamsters within a sealed 2L

384 chamber; (B) Air was collected from anesthetized hamsters using a nosecone. (C) Aerosol

385 particle emission rate from uninfected hamsters $(n=4)$ in the chamber (filled circles) or by

386 nosecone (open circles). ${ }^{*} \mathrm{p}<0.05$. 

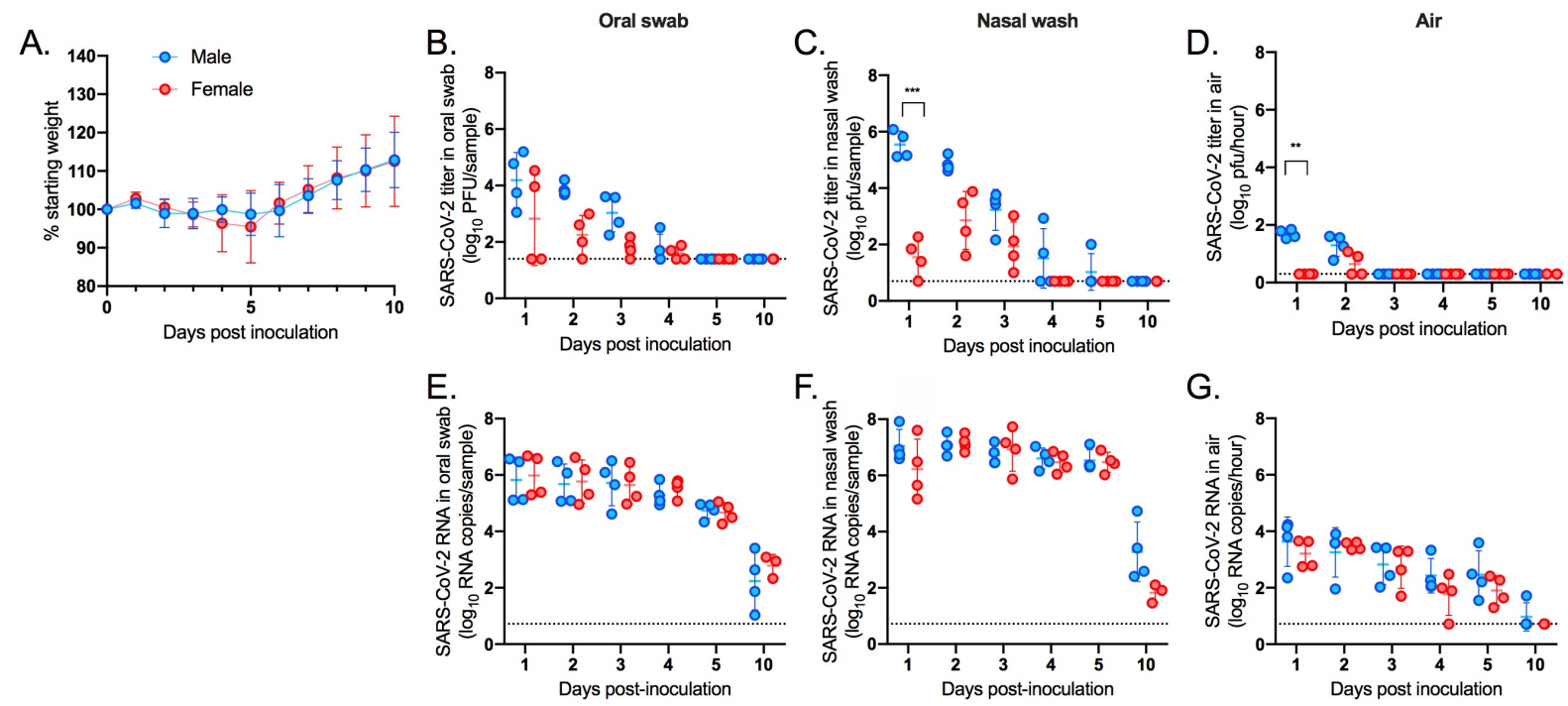

389 Figure 2. Shedding of SARS-CoV-2 in aerosols. Male $(n=4)$ and female $(n=4)$ hamsters were

390 inoculated intranasally with SARS-CoV-2. (A) Percent starting weight; (B) Viral titers in oral swabs;

391 (C) Viral titers in nasal washes; (D) Viral titers in air samples; (E) Viral RNA levels in oral swabs; (F)

392 Viral RNA levels in nasal washes; (G) Viral RNA levels in air samples. Dashed line represents limit

393 of detection. ${ }^{* *} p<0.01 ;{ }^{* * *} p<0001$. 
A.

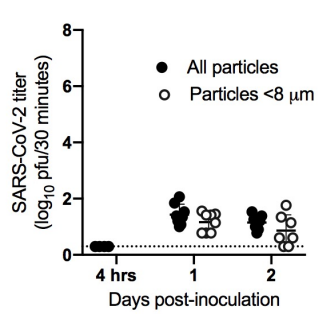

B.

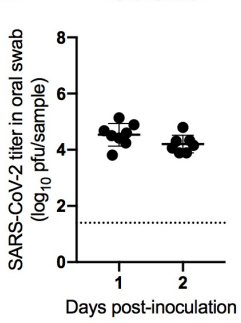

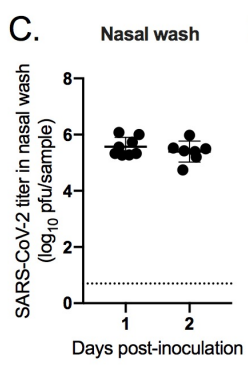

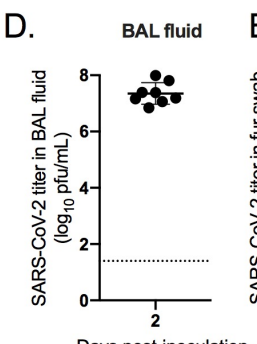

Days post-inoculation

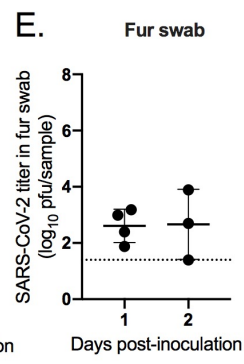

396 Figure 3. Aerosols $<8 \mu \mathrm{m}$ contain SARS-CoV-2. Male hamsters $(n=8)$ were inoculated

397 intranasally with SARS-CoV-2. (A) Viral titers in total aerosols (filled circles) or those $<8 \mu \mathrm{m}$ (open

398 circles); (B) Viral titers in oral swabs; (C) Viral titers in nasal washes; (D) Viral titers in BAL fluid;

399 (E) Viral titers in fur swabs; (F) Viral titers in rectal swabs. Dashed line represents limit of

400 detection.

401 
(A) Size distribution from chamber

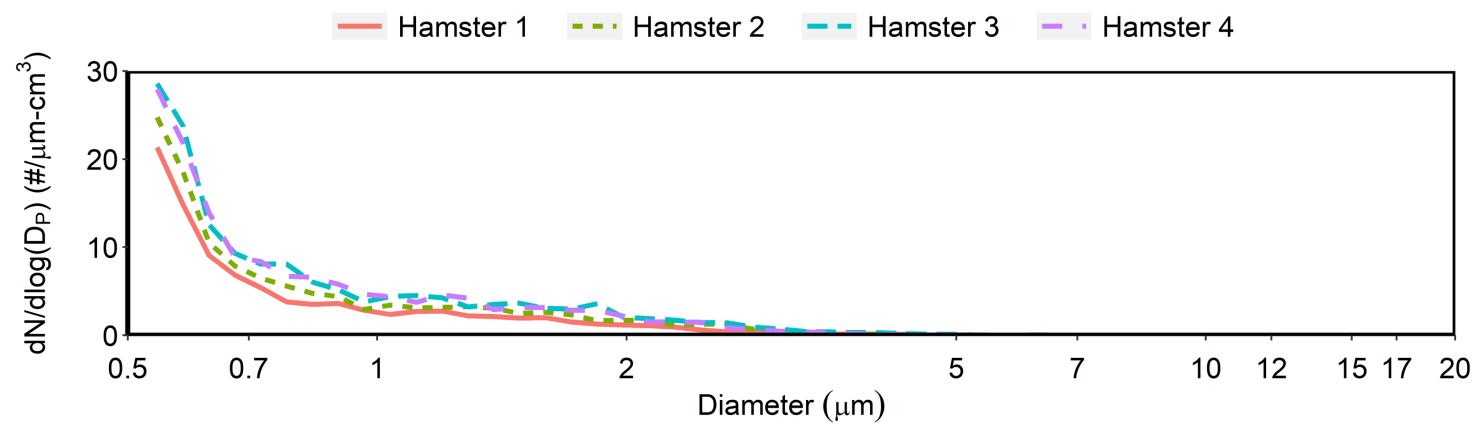

(B) Size distribution from nosecone

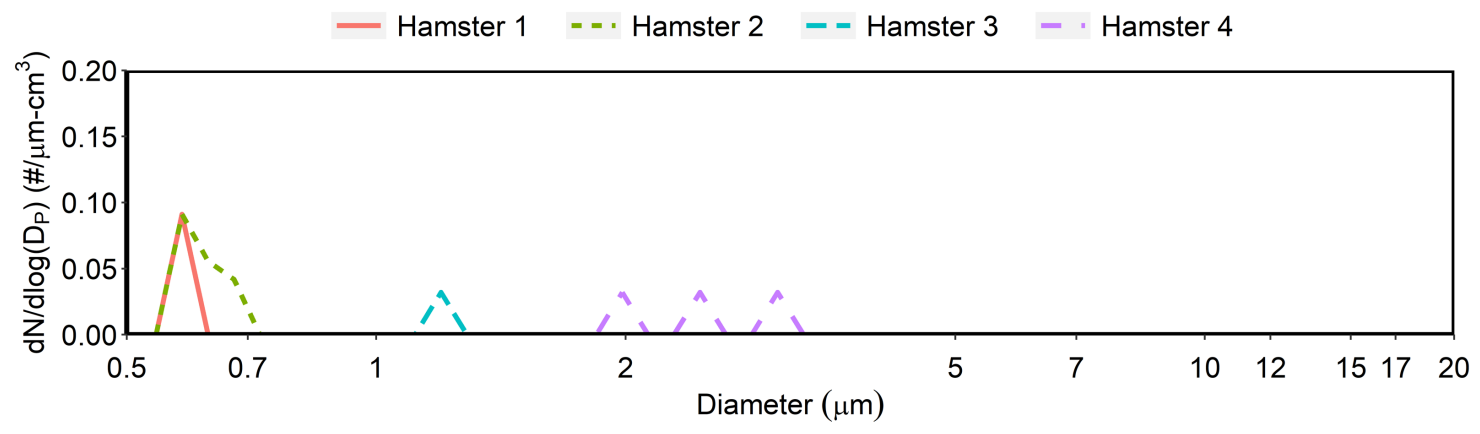

403 Supplementary Figure 1. Aerosol size distributions. Size distributions of aerosols generated

404 from uninfected hamsters $(A)$ in the chamber or $(B)$ through a nosecone. Each size distribution

405 curve was obtained at times corresponding to the highest aerosol particle concentration during

406 the 15-minute sampling period for each hamster. 